\title{
Pleasure and Its Contraries
}

\author{
Olivier Massin
}

Published online: 23 January 2014

(C) Springer Science+Business Media Dordrecht 2014

\begin{abstract}
What is the contrary of pleasure? "Pain" is one common answer. This paper argues that pleasure instead has two natural contraries: unpleasure and hedonic indifference. This view is defended by drawing attention to two often-neglected concepts: the formal relation of polar opposition and the psychological state of hedonic indifference. The existence of mixed feelings, it is argued, does not threaten the contrariety of pleasure and unpleasure.

What is the contrary of pleasure? "Pain" is one common answer. This paper argues that pleasure instead has two contraries: unpleasure and hedonic indifference. This view is defended by drawing attention to two often-neglected concepts: the formal relation of polar opposition and the psychological state of hedonic indifference, here called "indolence". Section 1 introduces the concepts of pleasure, pleasantness, contrariety, and contradiction, and argues that the contradictories of pleasures do not constitute a natural kind. Section 2 introduces the concept of polar opposition and argues that the real polar opposite of pleasure is unpleasure. Section 3 maintains that indolence is the neutral opposite of pleasure and argues (i) that indolences do exist, (ii) that they are sui generis episodes, and (iii) that they do not necessarily stand directly in the middle of the pleasure/unpleasure continuum. Section 4 addresses an objection to the project of identifying the contraries of pleasure, to the effect that mixed feelings entail that pleasure and unpleasure are independent orthogonal dimensions of experience.
\end{abstract}

\section{Hedonic Contrarieties}

\subsection{Pleasure and Pleasantness}

There is a broad range of positive hedonic affects, such as joy, gladness, contentment, merriment, glee, ecstasy, euphoria, exhilaration, elation, jubilation, happiness, felicity, bliss, enjoyment, amusement, fun, rejoicing, delectation, enchantment, delight, rapture, relish, thrill, satisfaction, gratification, jollity, gaiety, cheerfulness, relief, etc. Here I shall use the term "pleasure" in this most generic, encompassing sense, subsuming all of the items in the list above as well as other similar mental episodes. That is, pleasure,

O. Massin $(\bowtie)$

Department of Philosophy, University of Geneva, 2, rue de Candolle, 1211 Geneva, Switzerland e-mail: Olivier.Massin@unige.ch 
in the sense used here, covers the whole range of hedonically-positive affects. The comprehensive sense of the word we shall operate with here includes, to follow Sidgwick (1981, p. 127), "the most refined and subtle intellectual and emotional gratifications, no less than the coarser and more definite sensual enjoyments". That there is such an inclusive sense of the word pleasure is argued in detail by Katz (2006, n.1) and is standardly assumed by philosophers writing about pleasure. ${ }^{1}$

Not all uses of the term pleasure, however, are used in this comprehensive sense. In particular, when we say that an evening was "a pleasure", or that chocolate is "one's pleasure", we are using the term in a looser sense. Pleasure, in the strict sense, refers only to mental episodes. When we call an object or cause of pleasure "a pleasure", we are using the term metonymically. Though I shall here understand pleasure in the wide, comprehensive sense - including all hedonically-positive affects - I shall use it in the strict sense: all pleasures are mental episodes.

Yet not all mental episodes are pleasures. Following fairly common theoretical use, I shall call "pleasantness" the property, whatever it is, in virtue of which some mental episodes are pleasures. Pleasantness is what differentiates mental episodes that are pleasures from those which are not. Pleasantness is the essential and distinctive property of pleasures: pleasures are pleasant mental episodes. (Note that pleasantness, as it shall be used here, is consequently only a property of mental episodes, in contrast to its ordinary use, which licenses talk of pleasant wines or dinners)

\subsection{Contrariety}

Contrariety will be considered a relation between predicates or properties. Pleasures, being neither predicates nor properties, have, strictly speaking, no contraries. What do we mean, then, when we enquire about the contraries of pleasure? Speaking about the contraries of pleasure, I submit, is only shorthand for speaking about the contraries of pleasantness. The question "What are the contraries of pleasure?" can be rephrased: "What are the contraries of being pleasant?", or "What are the contraries of the essential distinctive property of pleasure: its pleasantness?".

Contrariety is a species of incompatibility. Incompatibility between properties is defined as follows:

Incompatibility: two properties are incompatible iff they cannot be exemplified by the same bearer at the same time.

Incompatibility, as it stands, is too rough a relation for our present purpose. Being pleasant and being sick are incompatible, for example, but this does not make sickness a property worth investigating here. Likewise, being odd and being creamy are incompatible, but this is not due to some genuine opposition between them, it is due to the fact that they do not apply to the same categories of bearers: only numbers can be odd, only concrete substances or stuffs can be creamy. Likewise, only mental episodes

\footnotetext{
${ }^{1}$ See e.g. Broad (1959, p. 230), Sidgwick (1981, p. 127), Von Wright (1963, p. 11), Alston (1967, p. 341), Sprigge (1988, p. 128), Johansson (2001, p. 39). Some philosophers prefer to use "enjoyment" instead of "pleasure" in order to refer to that generic concept (Crisp 2006, pp. 101-2). Some others use "happiness". For Hartmann (1932, vol. 2 p. 160), happiness is opposed to "suffering" and includes "pleasure, satisfaction, joy, blessedness".
} 
can be pleasant (in the sense retained here), whereas only living beings can be sick. Relying on earlier suggestions from Woods (1969), Barnes (1969), and Lehrer and Lehrer (1982), we will say that two properties are contrary when they are incompatible and apply to the same category of bearers. I shall rely here on some intuitive grasp of the notion of category of entities, which shall remain undefined.

Contrariety: two properties are contrary iff they are incompatible and have the same category of bearers.

The category of bearers relevant to pleasantness is mental episodes. So we are interested here in properties whose bearers are mental episodes and which are incompatible with the property of being pleasant.

\subsection{The Contradictory of Pleasure}

One contrary of the property of being pleasant is the property of not being pleasant, insofar as it accrues to some mental episodes. This property is the contradictory of the property of being pleasant.

Contradiction is primarily defined as a relation between sentences or propositions, but it might also be extended to properties. When applied to properties, contradiction is a special case of contrariety. ${ }^{2}$ Two properties are contradictories if they are contraries and if any bearer that does not exemplify one exemplifies the other. The properties of being pleasant and of not being pleasant are thus contradictories.

Contradiction: two properties are contradictory iff (i) they are contraries and (ii) if one is not exemplified by a bearer at time $t$, the other is exemplified by that bearer at time $t$.

That being pleasant has a contradictory, in this sense, is trivial. The substantive question is whether this contradictory property is a natural, bona fide property, or whether it is complex and heterogenous, lacking any intrinsic unity. Compare pleasure to knowledge or health: their contradictories-ignorance and illness (let us here assume) - correspond to terms in our lexicon, and one may wonder whether health, for instance, should be defined as a lack of illness, or, on the opposite, illness as lack of health. Does pleasure have a contradictory of this kind?

One influential view, going back to Plato's Philebus, is that pleasures should be defined in contrast to pains (or unpleasures). The most straightforward way to do this is to claim that any mental episode that is not a pain is a pleasure. Pleasure would then be an absence of pain, taken as the fundamental hedonic phenomena; pleasantness would boil down to a lack of unpleasantness.

\footnotetext{
2 This is meant to be true only for contradiction and contrariety when they operate upon predicables (or properties). That is, the claim is simply that if two predicates (or properties) are contradictory, then they are contraries. It is neither claimed nor entailed that contradictory propositions are contraries propositions. As argued by Geach (1969), thinking of contrariety as an operation applying to propositions might well be mistaken. In accordance with Geach, I shall not rely here on the controversial notion of contrary propositions; only contrary predicables will be appealed to: being pleasant, being unpleasant and being indolent.
} 
It is, however, doubtful that the contradictory of pleasantness constitutes a natural property. Pains (or unpleasures) do not exhaust non-pleasures. Nonpleasures also include episodes of hedonic indifference, which are neither pleasant nor unpleasant. Following Berkeley (1998, First Dialogue), I shall call such episodes "indolences". Indolence is preferable to hedonic indifference, for the latter refers to an attitude, and it should not be assumed here that pleasure, unpleasure, and the mental episode that mediates between them are necessarily attitudes (whether pleasures are all intentional is a controversial issue, see Massin 2013a for a positive answer). If pleasure is equated to the mere absence of pain or unpleasure, one has to deny the very possibility of episodes of hedonic indifference-indolences-which seems dubious (a worry raised by Burke 1767, Part I, sect. II, Marshall 1889, 433-4).

As it happens, no-pain theories of pleasure have generally tried to define pleasure on the basis of pain more subtly. Rather than equating pleasure with a mere absence of pain, most theories of this kind have equated it either with the cessation of pain (Von Frey, quoted by Titchener 1908, p. 82), or, more commonly, with a recovery from pain (Plato 1993; Verri 1781 and Kant 2006, Bk II, pp. 125 sqq, for bodily pleasures). These suggestions raise problems of their own (for instance, they appear to forbid pure pleasures, i.e. pleasures that are not preceded by pains), but for our purposes here, it is worth noting that they do not forbid indolences, and thus do not entail that pleasure and pain are contradictories.

So because the contradictory of pleasure includes two heterogenous kinds of episodes - unpleasant and indolent mental episodes - pleasure lacks a natural contradictory. As a consequence, pleasures cannot be defined by the negation of pain or unpleasure, nor are pain or unpleasure defined by the negation of pleasure. ${ }^{3}$ If pleasantness has any interesting contrary properties, they cannot be contradictory properties.

\section{The Polar Opposite of Pleasure: Unpleasure}

\subsection{Polar Opposition}

If pain and pleasure are not contradictories, could they be some other kind of opposites? Let us use the term "opposition" to refer to all the species of contrariety between properties that are not cases of contradiction.

Opposition: two properties are opposites iff (i) they are contraries (ii) they are not contradictories.

There are several kinds of opposition. For instance, if pleasure varies in degree, then pleasures of different degrees are scalar opposites. Scalar opposition concerns properties that belong to the same order - typically gradable predicates - such as being $10 \mathrm{~m}$

\footnotetext{
${ }^{3}$ To my knowledge, the only attempt to define pain on the basis of pleasure is to be found in Bouillier (1877, Chap. XII).
} 
long and being $11 \mathrm{~m}$ long, or being red and being blue. Whatever is (exactly) $10 \mathrm{~m}$ long is not (exactly) $11 \mathrm{~m}$ long, and whatever is (entirely) red, is not (entirely) blue.

Scalar opposition: contrariety between properties that belong to the same order.

That is, no pleasure can be pleasant to degree $n$ and to degree $n+1$.

One other important kind of opposition is the relation of polar opposition. Polar opposition relates, for instance, the properties of being good and of being bad; or the property of being a positive real number and the property of being a negative real number. Semantic antonyms typically express polarly opposed properties.

Though it is often appealed to, the concept of polar opposition is rarely addressed as such. As far as I know the study of polar opposition has mostly concerned linguists (see e.g. Lehrer and Lehrer 1982, Horn 1989; Cruse 1995, Chap. 9, 10, 11). Despite much valuable discussion, however, some metaphysical work remains to be undertaken.

One definition of polar opposition inspired by Barnes (1969) claims that two properties $F$ and $G$ are polar opposites if and only if they are contraries, and for every property $H$ which is contrary to both $F$ and $G, H$ is "between" $F$ and $G .{ }^{4}$ Contrary to all the other predicates of the order, the extremes of an order are not themselves between other predicates of the order. Thus gray is between black and white, but white is not between gray and any other predicate of that continuum. The polar opposition defined by Barnes relates not just any predicates of an order, but only the farthest predicates. This definition of polar opposition takes up the Aristotelian idea according to which the extremes or boundaries of an order or continuum are in a specific relation of opposition (Horn 1989, p. 37). The "betweenness" that is appealed to in this definition suggest that predicates $F, H$, and $G$ are ordered. If such an opposition indeed holds only between ordered predicates, then it is a sub-species of scalar opposition. Rather than calling it polar opposition, I shall call it "scalar opposition between extremes", or, for short, "extreme scalar opposition":

Extreme scalar opposition: contrariety between properties that belong to a same order and that bound this order.

The reason why we should speak here of extreme scalar opposition rather than polar opposition is that there is at least one other kind of opposition that in fact better deserves to be labelled "polar opposition". This kind of polar opposition will be needed to understand the opposition between pleasures their true polar opposites. Extreme scalar opposition captures the opposition between black and white, bald and hirsute, the farthest and the closest. Such extreme scalar opposites are not properly polar opposites.

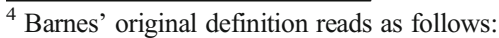
$\mathrm{C}_{3}(\mathrm{~F}, \mathrm{G})=(\mathrm{x})((\mathrm{RF}=\mathrm{RG}) \&(\mathrm{Gx} F \mathrm{Fx}) \&((\mathrm{H})((\mathrm{RH}=\mathrm{RF}) \&(\mathrm{H} \neq \mathrm{F}) \&(\mathrm{H} \neq \mathrm{G}))(\mathrm{H}$ is between $\mathrm{F}$ and $\left.\mathrm{G})))\right)$ (Barnes 1969)

Where " $\mathrm{C}_{3}$ "means polar opposition and " $\mathrm{R}$ " means the range of a predicate.

Incidentally, one objection to it runs as follows: $\mathrm{F}=$ black, $\mathrm{G}=$ white, $\mathrm{H}=$ visually extended. It is true that visual extension and color have the same range (whatever is colored is visually extended and whatever is visually extended is colored). It is not the case however that $\mathrm{H}$ is between $\mathrm{F}$ and $\mathrm{G}$ (in any intuitive sense). So according to Barnes' definition black and white would not be polar opposites (he himself claims that they are). By requiring that $\mathrm{H}$ be contrary to both $\mathrm{F}$ and $\mathrm{G}$, my definition above avoids this problem.
} 
Terms like good and bad, desire and aversion, love and hate, positive and negative charges are polar opposites in the sense I am interested in here. Here are three differences between extreme scalar opposition and true polar opposition:

1. Predicates that do not express extremes of an order can be polarly opposed. The most beautiful is indeed polarly opposed to the ugliest. But the quite beautiful and the quite ugly are polar opposites as well.

2. The orders to which polar opposites belong include a natural null value, an “indifference zone" (Lehrer and Lehrer 1982) or "pivotal region"(Cruse 1995, p. 205): thus between the good and the bad one finds the axiologically neutral, between desire and aversion one finds the motivationally indifferent, between love and hate one finds the emotionally indifferent. No such null value is essentially found between extreme scalar opposites: when traveling from black to white one never crosses a colorless point. (True, on can, by stipulation, define some shade of grey as the neutral color, and assign to it the value "zero". But this would be an arbitrary, fiat, zero-value, not a natural or bona fide zero, as is the axiologically neutral or emotionally indifferent. See 2.3 below)

3. Relatedly, the orders to which polar opposites belong are essentially polarized, unlike the orders of extreme scalar opposites: love, goodness, desire, and positive charge fall on the positive side of their respective orders, while hate, badness, aversion and negative charge fall on their negative side. On the other hand, whiteness and baldness are neither essentially positive nor essentially negative.

While extreme scalar opposition captures the relation between the farthest points of an order, polar opposition captures the relation between properties that fall on a distinct side of a neutral point.

Polar opposition: contrariety between two properties falling on both sides of an indifference point.

Polar opposition and extreme scalar opposition are independent. Black and white, bald and hirsute are extreme scalar opposites but not polar opposites, because of the lack of a neutral pivotal point.-2 and +2 , or mildly good and mildly bad, are, on the other hand, polar opposites, but they are not extreme scalar opposites. The worst and the best are both extreme scalar opposites and polar opposites.

\subsection{Unpleasure: The Polar Opposite of Pleasure}

What, then, is the polar opposite of pleasure? It has often be claimed that pain is the polar opposite of pleasure (e.g. Locke 2008, Bk II, sec. II, XX, Bentham 1996, chap. IV, V, Bain 1859, pp. 21, 32, Bain 1875, p. 12, Hamilton 1882, vol. 2, pp. 436-7, Marshall 1894, Sidgwick 1981, Bk II, Chap. II, §2, p. 125). Yet this claim lays itself open to two kinds of objections:

1. The first objection grants that pain is one polar opposite of pleasure, but denies that is it the only polar opposite. Pain would be too narrow to encompass all of the polar opposites of pleasure. First, because pain is often restricted to bodily sensations, 
while pleasure encompasses not only bodily pleasures but also pleasures of the mind. Second, because even when we focus on bodily pleasure, many of its polar opposites are not correctly called pain: for example itching, nausea, feeling cold, hunger, and exhaustion are not painful episodes, but are, arguably, polarly opposed to bodily pleasures. Russell $(1995,71)$ suggests that "discomfort" is a better way to capture the entire span of bodily unpleasures that are opposed to bodily pleasures. Third, and relatedly, pains, contrary to bodily pleasures, appears to have something in common apart from their being typically disliked or suffered. In Trigg's (1970, Chap. VI) terms, while there is an intrinsic "pain-quality" shared by all physical pains, there is no intrinsic "pleasure-quality" shared by all bodily pleasures (see also Aydede 2000 for converging empirical worries about pleasure-qualities).

2. The second objection is more radical, arguing that pain is not even a polar opposite of pleasure. The idea is that pain and pleasure belong to different categories, and therefore cannot be opposites. Pain is a quality on a par with other sensory qualities (see, e.g., Von Wright 1963, p. 70; Wohlgemuth 1917, p. 437, 450; Russell 1995, p. 70; Ryle 1954). Pleasure, by contrast, is a kind of mental episode. As such, opposing pain and pleasure is as misleading as opposing redness and desiring.

One possible answer to this objection is that "pain" does not always name a sensory quality, but instead ambiguously denotes either a pain-quality or a pain-experience. Pain, understood as an experience rather than a quality, is one polar opposite of pleasure. As a reply, I suggest that for both pain and pleasure there are both strict and loose senses, but the relation between these two senses goes in the reverse direction in each case. That is, while "pleasure" in the strict sense, as we have seen, refers to mental episodes, but might be used derivatively to name the causes or objects of these episodes; "pain" in the strict sense refers to a sensory quality which is the object or cause of some experience (feeling pain, suffering pain), and might be used derivatively to name those experiences themselves. ${ }^{5}$ While it is natural to call some experience (of a good wine, for instance), "a pleasure", it seems more contrived to call the sensation we get when entering a hot bathrather than our experience of it-“a pleasure". Yet while it is natural to call "pain" some localizable qualities experienced in our body, it seems more forced to call "pain" our very suffering of these pain-qualities. Strictly speaking, we can have a pain, but not a pleasure, in our foot. If this is right, pain and pleasure in the strict sense are indeed not polar opposites.

There is, however, some grain of truth in the claim that pleasure and pain are opposites. Suppose that pleasure is an intentional episode of taking pleasure in, enjoying, or being pleased by something, and that pains are sensory qualities. Then it is presumably incorrect to take pleasure in pain, to enjoy pain, or to be pleased by pain.

All in all, the polar opposite of pleasure, in the comprehensive and strict sense, should not be called "pain". Here I shall use "unpleasure" as the polar of opposite of "pleasure" (see also Hume 2000; Mezes 1895; Wohlgemuth 1917, p. 437; Russell 1958; Plochmann 1950; Findlay 1961; Rachels 2004; Mulligan 2009). Similarly to pleasure, the essential

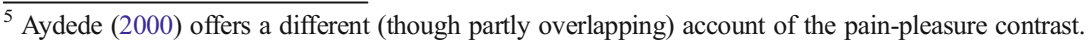


and distinctive property of unpleasure is unpleasantness. An unpleasure is an unpleasant mental episode. Thus we have the following first hedonic square (Fig. 1).

In the strict sense, this square of opposition is not only hedonic, for it includes episodes that are not pleasures (indolences and unpleasures). Marshall (1894, p. 9) has conveniently introduced the term "algedonic" to cover both pleasure and unpleasure, ${ }^{6}$ and phenomena related therewith. I shall here adopt the following definition:

algedonic episode: episode which is either a pleasure, an unpleasure or an indolence.

One might use the term "algesic" to cover the unpleasant phenomena: an algesic episode is nothing but an unpleasure; an algesic object is the intentional object of an unpleasure; and algesic value is the value of an unpleasure, etc.

These distinctions are recapped in Fig. 2.

\subsection{Real Polar Opposition}

Polar opposition, as defined above, is a species of contrariety that comes in different sub-species. For instance, (i) the opposition between the obligatory and the forbidden, (ii) the opposition between positive and negative temperatures, and (iii) the opposition between the good and the bad correspond to very different kinds of polar opposition, as we shall now see. If we are to be clear about the opposition between pleasure and unpleasure, and later about the nature of indolences, we need to understand exactly which kind of polar opposition pleasure and unpleasure take. I shall argue that the polar opposition between pleasure and unpleasure is of the same kind as the good/bad opposition (see Klocksiem 2010 for a similar point).

The obligatory and the forbidden, the hot and the cold, the good and the bad are polar opposites according to the definition above: in each case, we have two contrary predicates separated by a neutral point: ${ }^{7}$ the optional lies between the obligatory and the forbidden, $0{ }^{\circ} \mathrm{C}$ lies between positive and negative temperatures, and the axiologically neutral lies between the good and the bad. While good and bad are real polar opposites, I shall argue that the obligatory and the forbidden and hot and cold are only pseudo polar opposites. Why?

First, the obligatory and the forbidden, like the necessary and the impossible, are duals of each other. This means that the following equivalences hold:

$p$ is necessary $\Leftrightarrow$ not $p$ is impossible.

$p$ is obligatory $\Leftrightarrow$ not- $p$ is forbidden.

But no such equivalences holds for the good and the bad, and neither do they hold for thicker values:

$* p$ is $\operatorname{good} \Leftrightarrow$ not $-p$ is bad.

$* p$ is admirable $\Leftrightarrow$ not- $p$ is despicable.

\footnotetext{
${ }^{6}$ See also Stumpf (1928, p. 68, n. 1) and Titchener (1908, p. 338 n. 5).

${ }^{7} \mathrm{I}$ am here treating obligatory and forbidden, and necessary and impossible, as well as good and bad, as predicates, but the same remarks hold, mutatis mutandis, for the sentential operators 'it is obligatory/necessary/ forbidden ... that ...'. I intend to remain neutral on the question of whether alethic modalities, norms, and values are better construed in terms of operators or predicates.
} 


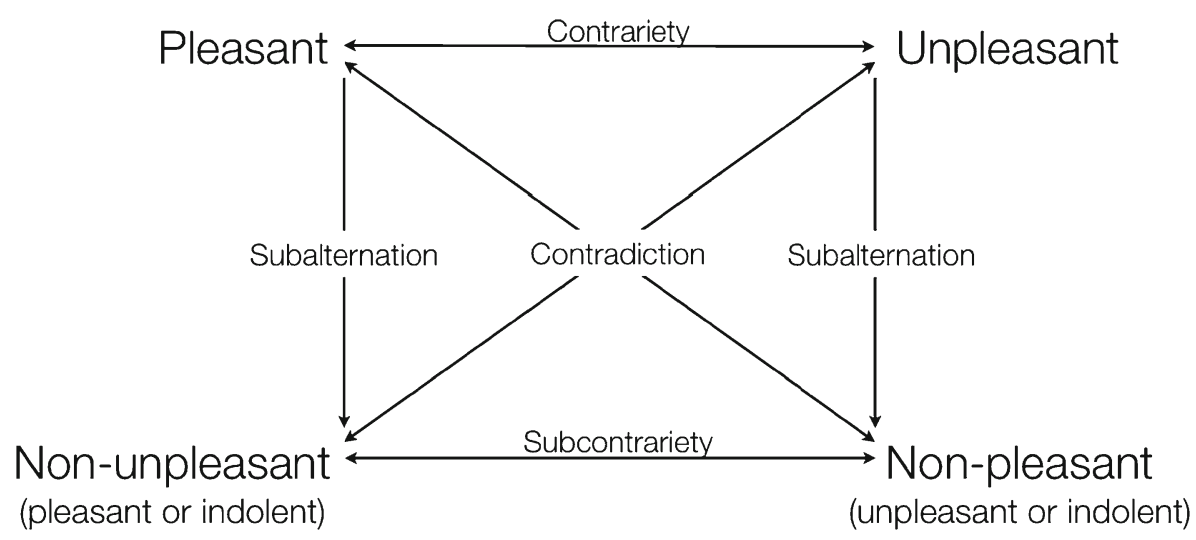

Fig. 1 The hedonic square (pleasant/unpleasant)

Because of these first equivalences it is possible to maintain that the necessary and the impossible are not fundamentally two different kinds of modal properties (or operators, see note 7), but are one kind of modal property that sometimes has positive complements, and sometimes negative complements. The same holds for deontic properties/operators. It is possible to maintain, for instance, that the obligatory is the only genuine deontic modality, and that the forbidden that $p$ just consists in the obligatory that not- $p$. If this is right, obligation and interdiction, necessity and impossibility are not really polarly opposed, for they are not really distinct. But this is not so with values and disvalues: the fact that it is elegant to wear a hat is not equivalent with the fact that it is inelegant not to wear a hat. The opposition between elegance and inelegance does reflect a real, irreducible, axiological difference.

A different kind of pseudo-polar opposition is the opposition between positive and negative temperatures. It is only by convention that $+2{ }^{\circ} \mathrm{C}$ and $-2{ }^{\circ} \mathrm{C}$ are polar opposites. ${ }^{8}$ The very same temperatures, measured in degrees Fahrenheit become mere scalar opposites. Given any single-dimensional continuum, one might assign a zerovalue to an arbitrary point and then define as positive and negative the values lying on either side of it. All we get here is arbitrary polarity: the very same continuum could have been ascribed a different polar structure, or no polarity at all. Temperatures are really only scalar opposites. Bipolar temperatures scales artificially polarize temperatures. This is not so with the good and the bad: the axiologically neutral is not a matter of conventionally ascribing the value 0 to some point of the axiological continuum. The neutral corresponds to a bona fide, natural, joint-carving point in the axiological space.

By pseudo-polar opposition, I mean a polar opposition that relates the linguistic representation of some phenomena, but which might not find counterparts in these phenomena themselves. By real polar opposition I mean a metaphysical relation that occurs not (only) at the representational level, but at the level of the things represented:

Pseudo-polar opposition: contrariety between predicates falling on both sides of an indifference point, which does not necessarily correspond to any such contrariety between the properties expressed by those predicates.

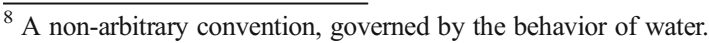




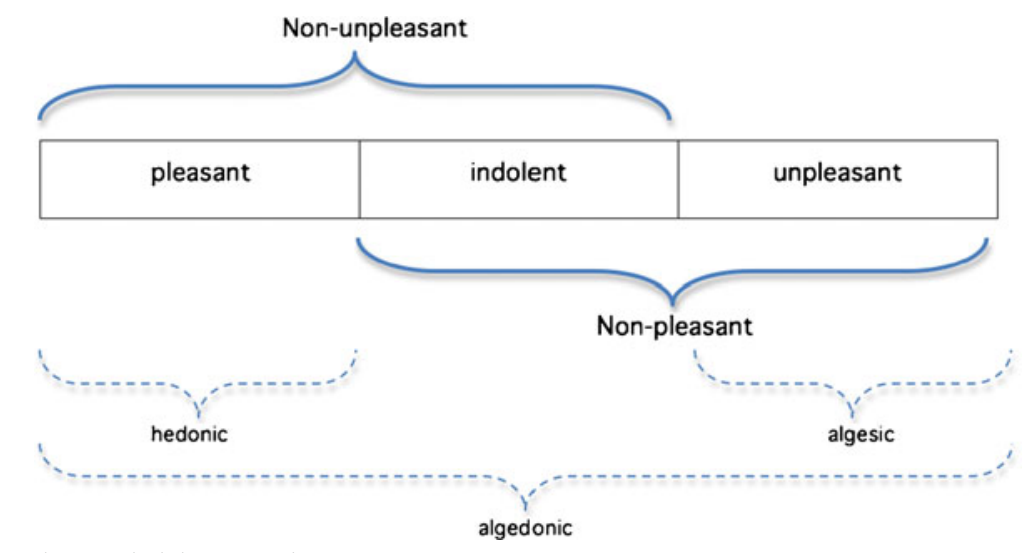

Fig. 2 Pleasure, indolence, unpleasure

Real polar opposition: contrariety between predicates falling on both sides of an indifference point, which corresponds to an analogous contrariety between the properties expressed by those predicates.

The different kinds of incompatibility between properties met so far are recapped in (Fig. 3). Now, while obligation and permission, and positive and negative temperatures, are pseudo-polar opposites, pleasure and unpleasure, like good and bad, are real polar opposites. For, first, the sentential operators "it is pleasant that" and "it is unpleasant that" are not each other's dual ("it is pleasant to swim" is not equivalent to "it is unpleasant not to swim"); and neither are the adjectives pleasant and unpleasant duals: "swimming is pleasant" is not equivalent to "not swimming is unpleasant".

Second, the indifference point lying between pleasure and unpleasure-indolencecorresponds to a non-arbitrary type of mental episode, which is not fixed by sheer convention. There is a bona fide, natural demarcation between pleasure and unpleasure: indolence carves the algedonic space along its unique joint. Something special happens at this point. What, exactly, is what we shall try to elucidate in the next section.

\section{The Neutral Opposite of Pleasure: Indolence}

\subsection{Neutral Opposition}

A last kind of opposition, entailed by the concept of polar opposition between properties, is the contrariety between any of the polar opposites and the neutral point lying between them.

Neutral opposition: contrariety between polar opposites and the neutral point that separates them.

For instance, the good and the bad are each neutrally opposed to the axiologically neutral.

As mentioned above, the neutral opposite of pleasure (and of unpleasure) is indolence. A mental episode is an indolence only if it is neither an episode of pleasure nor an episode of unpleasure. Seeing, for instance, is usually indolent. Indolence is the 
neutral opposite of pleasure. For the sake of completeness, this leads to two other hedonic squares of oppositions (Figs. 4 and 5):

A first question about indolences is whether we are ever in such states. I shall argue that we are (3.2). A second question about indolences is whether such states are merely mental episodes that lack any algedonic property, or whether they are mental episodes exemplifying a sui generis property of being indolent. I shall argue that indolences do exemplify some sui generis algedonic property (3.3). One final question about indolences is whether they are situated in the middle of the pleasantunpleasant continuum, or whether they stand closer to one of its ends. I shall suggest that if there exist higher and lower forms of pleasure, indolences might not stand in the same place for each type (3.4).

\subsection{Do Indolences Exist?}

Are there some mental episodes that are neither pleasant nor unpleasant? This question might sound almost uninteresting nowadays, for its answer appears to be trivially positive. But this has not always been the case. The question was intensively debated at the end of the nineteenth century, and most psychologists and philosophers at that time rejected indolence: Hamilton (1882, vol. II, p. 433), Lotze (1888, I, p. 242 sqq), Lipps (1903. See Fréchette 2013 for an overview), Brentano, (1995, p. 147 sqq., who also presents other proponents of this view), Schlick (1962, p. 37), Beebe-Center (1965, p. 7). On the other side, Bain (1859, p. 35), Mill (1869, chap. 17, p. 184) and Külpe (1895, §36 pp. 242-3) were among the rare defenders of indolence. ${ }^{9}$ Brentano finally gives up his view that there are no indolences in the Appendix of the later 1911 edition of the Psychology (1995, p. 276), as well as giving up the claim that visual and auditive perceptions are always intrinsically pleasant or unpleasant.

Here are two of the main arguments put forward against indolences:

1. First, enemies of indolences insist that all ordinary experiences are always experienced as either slightly pleasant or slightly unpleasant. "It cannot be denied", Brentano writes, "that a certain faint feeling of pleasure is connected with a faint sensation of light" (Brentano 1995, p. 150). That sensations of light are always pleasant seems controversial. This clash of intuitions might be due to the fact that in the era of electricity and electronics we have become so accustomed to ubiquitous lights that we do not feel pleasure seeing them anymore.

2. Beebe-Center (1965, p. 7) presents a more empirically documented argument against indolences: some subjects he studied consider some stimuli indifferently, while still considering some of those indifferent stimuli to be more pleasing than the others. This, according to him, shows that the concept of indifference

\footnotetext{
${ }^{9}$ Earlier, Burke (1767, Part I, sect. II) defends indolences against the view that pleasure is the negation of pain alluded to above. Stout (1902, vol. 2 p. 288) grants that there can be indolences, but only after the impression of pleasantness or unpleasantness becomes faint due to habit. Sidgwick (1981, pp. 124-5) defends the existence of indolences, which he refers to as the "hedonistic zero", but urges that it does not constitute the "normal condition of our consciousness". Likewise Marshall (1894, pp. 57-8, 244-5) insists that states of indifference are seldom reached: our mental episodes are usually pleasant or unpleasant, but often to such a small degree that we do not notice it.
} 


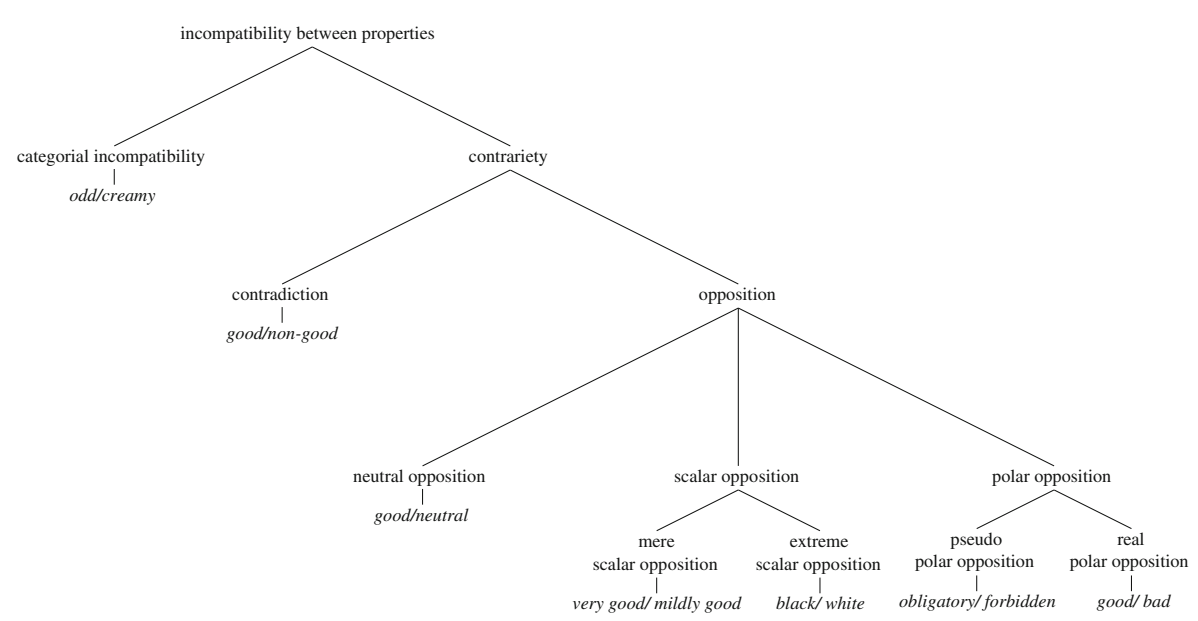

Fig. 3 Varieties of property incompatibility

does not express a null point, but a range of slight pleasantnesses and slight unpleasantnesses.

Note first that the argument threatens to overgeneralize, for the same will be true for each degree of pleasure or unpleasure. If a subject considers some stimuli as pleasing to degree $n$, he might by the same line of thought consider some of these stimuli to be more pleasing than others. If so, degrees of pleasantness/unpleasantness don't express points, but rather ranges of the algedonic continuum, which seems odd.

Second, and more importantly, such an argument is a non-sequitur. That we tend to call "indifferent" stimuli or sensations that are not so, does little to show that none are indifferent. It remains open, in particular, that among the stimuli or sensations we call "indifferent", some are truly so. Beebe-Center's observations show at best that our concept of a fully determinate state of indifference, or indolence, is not easily applied. It does not show that this concept is meaningless, nor that it is never correctly applied.

These two arguments against the existence of indolences are inconclusive, but there is also an argument in favor of their existence. One reason to think that indolences exist is that, passing continuously in experience from pleasure to unpleasure, we have to pass through a hedonically neutral state. ${ }^{10}$ We do not necessarily jump directly from the least pleasure to the least unpleasure. Here are two examples:

- $\quad$ The feeling of the hotness of the water, when entering the bath, is very pleasant. It becomes less and less pleasant with time, and sometimes unpleasant when the water is too hot. Experiencing such a transition from pleasure to unpleasure, there might well be a time at which the feeling of the hotness of the water is neither a pleasure nor an unpleasure.

- The first hearing of a simple melody might be pleasant, the second a little less pleasant, until the melody is heard so many times that hearing it becomes in the end

\footnotetext{
${ }^{10}$ See Sidgwick (1981, p. 125) for a version of this argument. One version was put forward by Wundt, see Brentano (1995, p. 149).
} 


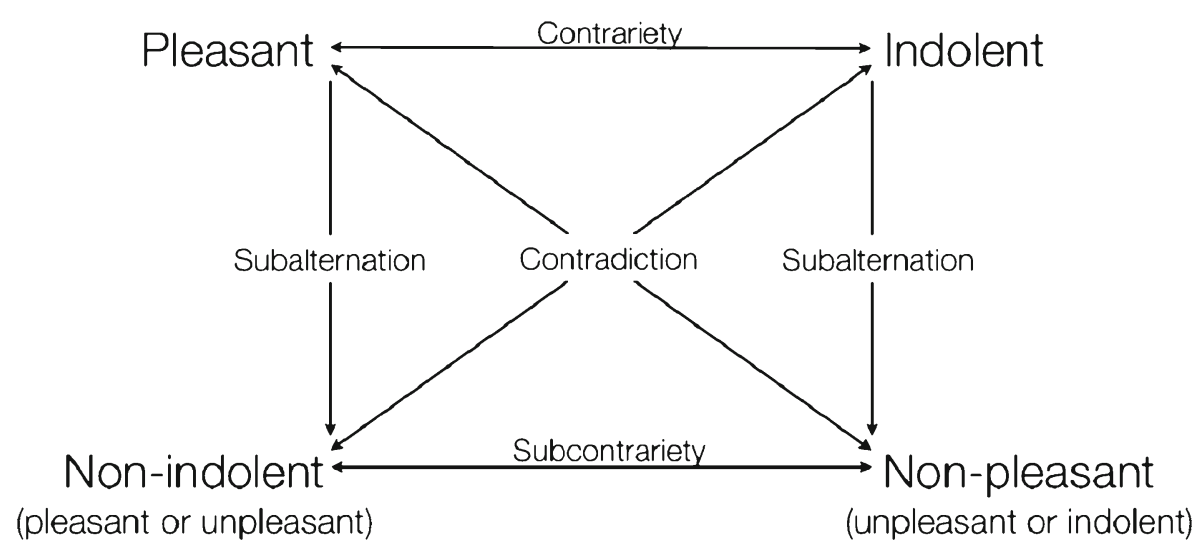

Fig. 4 The hedonic square (pleasant/indolent)

very unpleasant. Between the first pleasant hearing and the last unpleasant one, there might be a hearing of the melody which is indifferent.

The claim here is not that we necessarily pass through such a state of indolence when passing from pleasure to unpleasure. We might sometimes jump from pleasure to unpleasure. The point, rather, is that it would be ad hoc to claim that this is necessarily the case.

As an answer to this argument in favor of indolences, the early Brentano grants that there are specific states of indifference between states of pleasure and unpleasure, but he claims that indolences are not to be construed as episodes which are neither pleasant nor unpleasant. Indolences, he says, are better conceived of as episodes both pleasant and unpleasant to the same extent:

I myself am very doubtful whether [...] the sensations which occur between decidedly pleasant and decidedly unpleasant sensations should not rather be described (in accord with John Stuart Mill) as sensations which contain a mixture of pleasure and displeasure such that neither of them is predominant over the other. (Brentano 1995, p. 149, see also p. 151)

Moving from pleasure to unpleasure, we would never pass through a state devoid of pleasantness and unpleasantness, but only through a state of mixed feelings, in which pleasantness and unpleasantness compensate each other. Brentano might appear here to be denying the contrariety of pleasantness and unpleasantness (see Section 4 below on mixed feelings), but this is ultimately not the case. His claim is that in travelling from pleasure to unpleasure it is not the very same sensation that is both pleasant and unpleasant at once, but two different concomitant sensations. He gives the following example: sensations of light or brightness are even more pleasant when they are intense, but looking at the sun is painful. It would be a mistake, he claims, to think that the same sensation of light that was pleasant had suddenly become painful. The pain we experience when looking at the sun qualifies a sensation that is distinct from the sensation of brightness, which remains pleasant. Brentano's view is therefore that 
although all component mental episodes are either pleasant or unpleasant, some resultant episodes, made up of several component pleasures and unpleasures, might be indolent, not in the sense of being neither pleasant nor unpleasant, but in the sense of containing as much pleasantness as unpleasantness.

I agree with Brentano that it is not the sensation of light that is unpleasant when we look at the sun, and that in such cases one might never be in an indolent state: rather we have first an increasingly pleasant mental episode, which falls into the background of our consciousness or attention when an intense pain enters the scene. The point, however, is that this is not always so. When the same sensation ceases to be pleasant and becomes unpleasant, there is very likely a transitory episode during which it is indolent. One should, in any event, not conflate the idea that complexes of sensations might, on the whole, be neither pleasant nor unpleasant (in virtue of their component pleasures/unpleasures equilibrating each other), with the idea that simple mental episodes might be neither pleasant nor unpleasant (Stout 1902; ${ }^{11}$ Edwards and Ostrom 1971). It is this second idea that is at stake here: I have argued that simple mental episodes can be neither pleasant not unpleasant.

\subsection{Are Indolences Sui Generis Algedonic Episodes?}

One puzzling question is whether indolences consists merely in mental episodes that lack pleasantness and unpleasantness or whether they exemplify some genuine, sui generis property in virtue of which they are indolences? Pleasantness and unpleasantness, the essential properties of pleasures and unpleasures, are standardly though to be sui generis properties (theories identifying pleasures as the absence of pain, alluded to above, being exceptions). Do indolences in the same way, have to possess a sui generis property of being indolent, or is it enough for them to be neither pleasant nor unpleasant? Marshall (1894, p. 46) and Beebe-Center (1965, pp. 6-7) are among the few authors who mention this problem (Mulligan 1991, §4 compares Meinong's and Wittgenstein's positions on this issue; Balashov 1999 discusses this problem in the context of physical quantities).

One might rephrase the problem this way: we can pass from the very pleasant to the moderately pleasant. Are such steps of the same kind as the one between the slightly pleasant and the indolent? Travelling from the pleasant to the unpleasant, do we stay on the same algedonic continuum, or must we at some point step outside the hedonic continuum while still not having stepped into the algesic one? Is there anything like an algedonic continuum, or does the qualitative space of pleasure and unpleasure have a gap in the middle? If something weighs $0 \mathrm{~kg}$, it has no weight (admittedly, but see Balashov 1999). If something has a temperature of $0{ }^{\circ} \mathrm{C}$ it has a temperature. Is pleasure more, like weight or more like temperature? Are indolences algedonic states after all, or are they algedonic states of degree 0 ?

I shall argue that indolences are genuine algedonic states, which do not boil down to mental episodes that are neither pleasant nor unpleasant. I shall first reject an argument

\footnotetext{
${ }^{11}$ Stout clearly distinguishes between the question of whether some mental episodes are neither pleasant nor unpleasant from the question of whether our whole mental being, "our total consciousness", might be neither pleasant nor unpleasant overall. To this latter question he answers negatively.
} 
in favor of sui generis indolences, and then advance what I take to be a better argument to this effect.

\subsubsection{The Argument from the Unity of the Algedonic Space}

The first (bad) argument runs as follows:

P1 Pleasantness and unpleasantness belong to the same natural kind (i.e. algedonic kind).

P2 What unifies different degrees of pleasantness-unpleasantness is the fact that one can pass from any degree of pleasantness-unpleasantness to any other degree by a succession of continuous transitions.

P3 If the property of being indolent were merely an absence of pleasantnessunpleasantness, the algedonic space would be gappy in the middle: continuous transitions from any degree pleasantness to any degree of unpleasantness would no longer be possible.

C Being indolent is a sui generis property.

The argument relies on the idea that different determinate properties fall under the same determinable only if they are path-connected. Thus it has been claimed that what unifies all determinate phenomenal colors together is that one can travel from any determinate color shade to another by a succession of continuous gradations in the sense of of indiscriminable or "matching" steps (Helmholtz 1995, p. 345, Carnap 2002, p. 171, Goodman 1977, p. 43, Clark 1993, p. 140). If this is right, we have either to give up the claim that pleasantness and unpleasantness fall under the same bona fide determinable, or accept that indolentness is a sui generis algedonic property.

For this argument to go through, however, it has to be the case that quality spaces have to be unified through indiscrimination steps. But this is questionable. Note that this cannot be the only way to construe determinable properties, for such a strategy applies only to phenomenal determinables, i.e. qualities, such as color, sound, and maybe pleasantness. "Matching", or "indiscrimination" are psychological concepts that can be of no help in unifying, say, determinate physical weights or spatial lengths. Certainly, different weights or lengths have something in common independently of our apprehending them.

There are indeed other ways of accounting for the unity of determinates falling under the same determinable. Some have claimed that determinates of the same determinable are unified in virtue of possessing a common sui generis property, which is the determinable property itself. (Fales 1990, chap. 9, Elder 1996; Johansson 2000; Sprigge 1988, p. 137 assumes the existence of such determinable universals in his theory of pleasantness as a determinable property.) Another view has it that determinates are unified through brute relations of inexactitude. Determinables might just be maximal disjunctions of determinates whose resemblance is brute and inexact (Massin 2013b). If resemblance is construed, standardly, as an internal relation, necessitated by its relata irrespective of the attitude we take towards them, there is no need to rely on a psychological relation of indiscrimination to unify different determinate degrees of pleasure For instance, the least intense degree of pleasantness and the least intense degree of unpleasantness objectively 
resemble each other more than they resemble, say, a determinate color. According to such a construal of determinables in terms of brute resemblances between qualities, the space of qualities might be discontinuous: qualities on both side of the quality-break might still inexactly resemble each other. No path-connectedness between them is required. A gap in the pleasantness/unpleasantness space therefore does not necessarily threaten its unity. Discontinuous quality spaces might be genuinely unified. The unity of the algedonic space cannot be the reason why being indolent needs to be accepted as a sui generis property.

\subsubsection{The Argument from the Structure of the Algedonic Space}

A better argument in favor of the view that being indolent is a sui generis property, I submit, stems from the polar structure of algedonic space. In order for pleasure and unpleasure to be polar opposites, as we have seen, they have to hinge around a pivotal point of indifference. That is, indolence has to be between pleasure and unpleasure in order for them to be polar opposites. Now, if indolences were just mental episodes, lacking both pleasantness and unpleasantness, nothing would ground their intermediary location. Here is why.

Let us admit, as suggested above, that the pleasure-unpleasure space is structured by relations of brute inexact similarities. Pleasure is ordered from the most intense to the least intense, because extremely intense pleasures resemble very intense pleasures more than they resemble slightly intense ones (for simplicity's sake, let us here bracket the question of the different qualities of pleasures). The same holds for unpleasure. Somehow, indolence has to find its place in this space by virtue of its resemblance to faint pleasure and faint unpleasure. But indolence, construed as a mental episode that lacks both pleasantness and unpleasantness, does not resemble faint pleasure and unpleasure more that it resembles intense pleasure and unpleasure. Compare this to moral values. Is something that lacks any moral value - a piece of cheese, say-closer to things to that accrue the highest degree of moral goodness, or to things that are morally good only to a lesser degree? The question hardly makes sense. The same holds for indolences, construed as algedonically-naked episodes: if indolences lack any algedonic property, it is not the case that they are closer to faint pleasures than to intense ones. They fall outside the pleasure-unpleasure order. Consequently, algedonically-naked episodes cannot be pivotal points of the algedonic space. If the existence of an indifference zone is indeed essential to the polar structure of such property spaces, then such a zone cannot be a mere absence, but has to be a sui generis property. Hence being indolent should be regarded as a genuine property constitutive of the algedonic space, on a par with being pleasant and being unpleasant. For indolentness to be in the pleasantnessunpleasantness space, it has to be some fully-fledged, sui generis property. Only then can indolence be said to stand between faint pleasure and unpleasure, because it resembles them more that it resembles intense pleasure and unpleasure.

The property of being indolent has to be more than a mere lack or absence in order to explain the polar structure of the algedonic space. Consequently, some mental episodes are pleasant, some are unpleasant, and some are indolent. 


\subsection{Are Indolences Really in the Middle of the Algedonic Continuum?}

One last and rarely-raised question about indolence is whether it lies in the middle of the algedonic space. Is there, so to speak, more pleasure on its left, more unpleasure on its right, or an equal amount on either side? The pessimist has it that the worst suffering has no counterpart on the hedonic side. The optimist, on the contrary, takes it that no suffering could ever counterbalance the most intense joy. Hartmann (1932, vol. 2, pp. 464 sqq.) suggests a more subtle optimistic answer. He does not speak about indolence, however, but about the indifference-point in value scales. Is good is stronger than bad, or the reverse? Though pessimism might sound prima facie tempting (see e.g. Baumeister et al. 2001), Hartmann relies on a distinction between different heights of values to defend moderate optimism. He subscribes to the view that some value-types are higher than others. Heights of values characterize types of value - moral, aesthetic, epistemic, and so on-and should not be conflated with degrees of values, which characterize determinate values of a type. For instance, "justice is more important than elegance" is a statement about the relative heights of justice and elegance, while "Paul is more elegant than George" concerns the relative degrees of elegance of Paul and George. Hartmann's moderate optimism consists in the following: the higher a type of value is, the farther the indifference point will be from the highest degree of positive value:

In the case of the higher values the whole scale lies more above, in the case of the lower more below the indifference-point. (Hartmann 1932, vol. 2, p. 468)

This optimistic suggestion is easily transposed to the algedonic realm if one accepts the distinction between higher and lower pleasures. ${ }^{12}$ The idea would be that, for higher pleasures/unpleasures, the most intense pleasure lies far above the indifference-point (indolence) while the most intense unpleasure lies just below it. On the other hand, for lower pleasures/unpleasures, the most intense pleasure only slightly exceeds the indolence-point, while the most intense unpleasure lies far below that indolence-point (Fig. 6):

Suppose aesthetic pleasures are higher than bodily pleasures. The optimistic proposal then consists of two claims:

(i) The most intense positive aesthetic experience is far more pleasant than the most intense negative aesthetic experience is unpleasant. However unpleasant listening to a bad piece of music may be, its unpleasantness will never match, in absolute value, the pleasantness that accrues to the most intense enjoyment of a beautiful concerto.

(ii) On the contrary, for bodily pleasures, the worst pain will always, in absolute value, be more unpleasant that the highest pleasure is pleasant. We suffer intense pains, for example, more than we enjoy great massages.

\footnotetext{
${ }^{12}$ A distinction introduced, among others, by qualitative hedonists such as Mill (2002, chap. 2); Edwards $(1975,1979$.
} 


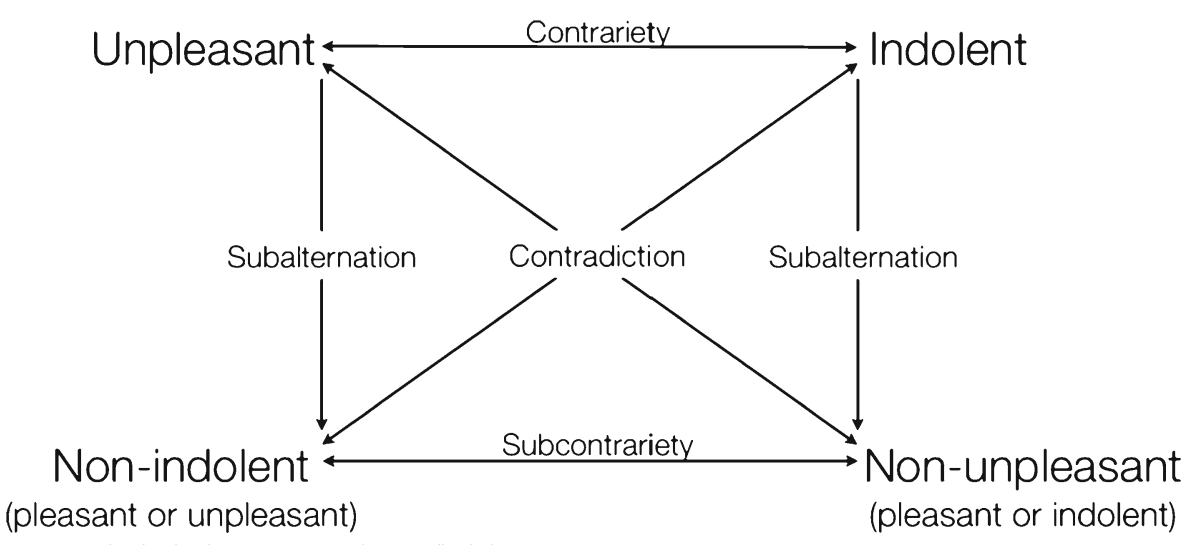

Fig. 5 The hedonic square (unpleasant/indolent)

Or, as the moderate optimist might say, the higher the pleasures are, the farther from the indolence point they stand. The hedonic pessimist will of course say the opposite; and the quietist will endorse the symmetry of the hedonic space.

\section{Mixed Feelings: Are Pleasure and Unpleasure Really Contraries?}

I have argued that pleasure has two natural contraries: indolence and unpleasure. In this final section, I address an objection to this proposal, according to which the possibility and actuality of mixed feelings entails that pleasure and unpleasure should not be construed as opposites, but instead should be construed as independent dimensions of variation of experience.

\subsection{Mixed Feelings}

That pleasure and unpleasure are polar opposites has been challenged on the grounds of the existence of mixed feelings. Mixed feelings occur when one subject has both pleasure and unpleasure at the same time. For instance, eating a chocolate cake while having headache, feeling sad but taking pleasure in smelling a lilac, having a cramp during an orgasm, feeling nostalgia (joyful sadness of remembering a happy time),

Higher pleasures

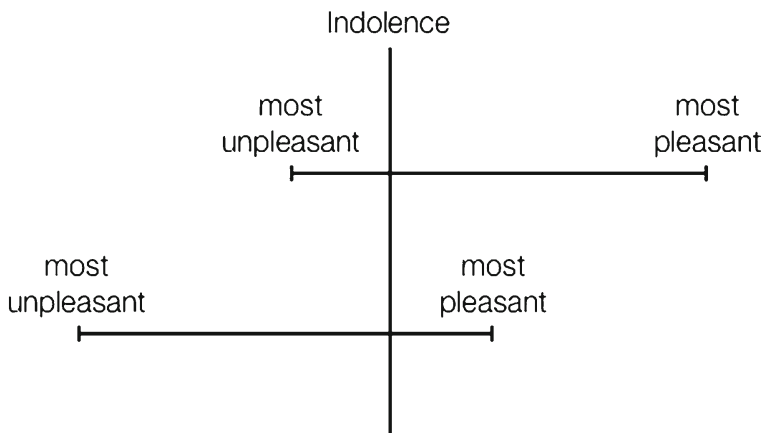

Fig. 6 Moderate optimism about higher and lower pleasures 
enjoying a tragedy, feeling ashamed of taking pleasure in listening to Michel Sardou, being delighting in eating a very hot curry, feeling relief at the death of a suffering relative, having fun on roller-coaster, being touched in receiving a gift that we don't like, enjoying endurance sports, feeling a pain decreasing, and so on.

Mixed feelings, when they consist in having several mental episodes at once, some pleasant, some unpleasant, hardly threaten the contrariety of pleasantness and unpleasantness. One potential source of error here is that contrariety is sometimes defined in terms of two properties not being possible in the same subject at once. If this were the case, one might be tempted to think that, since in cases of mixed feelings a same subject can be both pleased and displeased at the same time (but can't be sitting and standing at once for instance), pleasantness and unpleasantness are compatible properties. Or so the argument goes.

A moment of reflection suffices to see that the term "subject" has here been used equivocally, referring alternatively to the bearers of pleasantness/unpleasantness (which are not persons, but their mental episodes) or to the person having those mental episodes (see also Schimmack 2001). As long as it is not the very same mental episode that is both pleasant and unpleasant at once, the contrariety of pleasantness and unpleasantness remains untouched.

\subsection{Contrariety vs. Independence}

However, from the list of examples above, it appears that sometimes the very same mental episode is both pleasant and unpleasant. This is a more serious challenge to the view that pleasure and unpleasure are contraries. Some have drawn from this the conclusion that instead of being contraries, pleasure and unpleasure are not polar opposites, but are rather two independent dimensions of variation of experience. In the same way that colors vary along dimensions of hue, saturation, and brightness, algedonic experiences would vary along the distinct dimensions of pleasure and unpleasure. The same experience could be both pleasant and unpleasant to various degrees, pleasantness and unpleasantness being orthogonal dimensions. This position was first endorsed by Rehmke, who argues that "[p]leasure (Lust) and unpleasure (Unlust) are 'incommensurable dimensions', in the same way as sounds and colours" (Rehmke, quoted by Titchener 1908, p. 56).

More recently, refined versions of this view have been put forward by Diener and Emmons (1984), Watson and Tellegen (1985), Cacioppo and Berntson (1994), Watson (2000, pp. 26-33, 44-54), Larsen et al. (2004), Larsen et al. (2009), and Larsen and McGraw (2011), who all insist that the positivity and negativity of affects should be understood as independent, orthogonal dimensions. Let us call this view, according to which pleasantness and unpleasantness are not contraries, "INDEPENDENCE" 13; the view, defended here, according to which they are contraries, we shall call "CONTRARIETY".

Ambivalent reactions to the very same stimuli constitute one argument in favor of INDEPENDENCE. Such ambivalent reactions, upholders of INDEPENDENCE warn (correctly), are quite common and might be artificially concealed if subjects are only asked whether they feel positive or negative about a stimulus. Such kinds of questions

\footnotetext{
${ }^{13}$ The view is also called the "bivariate approach" — by contrast to standard "bipolar" approach — and is at the heart of the influential "Evaluative Space Model" of Cacioppo and Bernston (1994).
} 
do not allow them to report ambivalent emotional responses (Cacioppo and Bernston 1994). If subjects are asked how they feel about smoking, in terms of whether they feel positive or negative, their univocal answer (say, positive) might in fact conceal an ambivalent feeling. They might feel both positive (because they like smoking) and negative (because they want to quit smoking) about the habit. But given the phrasing of the question, and given that they feel more positive than negative overall about smoking, the answer they give misleadingly appears to report an unmixed feeling.

Though some have tried to argue that mixed feelings are impossible, ${ }^{14}$ or to question the empirical data supporting INDEPENDENCE (Russell 1979; Russell and Carroll 1999), I am here willing to grant the possibility of mixed feelings. In fact, I sympathize with the view that mixed feelings are ubiquitous; that, in Plato's terms, "there are combinations of pleasure and pain in lamentations, and in tragedy and comedy, not only on the stage, but on the greater stage of human life; and so in endless other cases" (Plato, Philebus, 50b). The problem with INDEPENDENCE is not its empirical premise; it is that this premise in the end does little to show that pleasantness and unpleasantness are not contraries.

\subsection{Mixed Feelings Do Not Entail INDEPENDENCE}

Why do cases in which the same conscious stimulus elicits at once pleasant and unpleasant reaction fail to undermine the contrariety of pleasantness and unpleasantness? Because conscious stimuli do not suffice to individuate mental episodes. The key issue is how finegrained one goes in the individuation of mental episodes, the bearers of pleasantness/ unpleasantness. As I have argued elsewhere (Massin 2011) if we examine at a fine-grained level we always dispel the apparent violations of contrariety. Compare the contrariety of colors. One sometimes needs to take into account very tiny colored areas to save the incompatibility of colors. ${ }^{15}$ Likewise, when one has ambivalent reactions to the same stimulus, one often needs to take into account quite subtle variations in order to see that pleasantness and unpleasantness do not, in fact, accrue to the very same bearer:

1. Our pleasure and our unpleasant reaction might target different aspects of the object or conscious stimulus (Tappolet 2005).16

2. Our pleasure and our unpleasant reaction may concern different ways in which this object, or its aspects, are presented.

3. Our pleasure might be extrinsic while our unpleasant reaction is intrinsic (see Feldman 1997, pp. 100 sqq. on extrinsic attitudinal pleasures).

\footnotetext{
$\overline{{ }^{14} \text { A view going back to Epicurus: }}$
}

Wherever pleasure is present, as long as it is there, pain or distress or their combination is absent. (Epicurus, Key Doctrines, 3-4, in Long and Sedley 1987, vol. 1, p. 115)

\footnotetext{
${ }^{15}$ Brentano (1979, chap. 3) even argues that in the case of multiple colors, such as orange, the places where the component colors lie (red/yellow) are distinct but too small to be sensorily differentiated (see Massin and Hämmerli 2014, for an assessment of this view).

${ }^{16}$ To the extent that the subjects consciously access the stimuli at stake in these studies, these stimuli might be equated to intentional objects.
} 
4. One of our reactions might be an "as if" or "make-believe" attitude (Duncker 1941), while the other is a serious reaction.

5. Our unpleasant reaction might be genuine, while our alleged pleasure is not genuinely a pleasure but just the indifferent belief or impression that this object is usually a source of pleasure (Young 1918).

6. In dependent mixed feelings, our pleasure might be a second-order pleasant reaction to a first-order unpleasant reaction (some masochists might react this way), or to the fact that this first-order reaction seems appropriate to us (some people might be happy to suffer because they think they deserve it; one might be glad to feel guilty because one thinks this is the right reaction, etc.)

Further options are conceivable, but the idea is that when one takes into account all the possible refinements in mental episodes, it is never the very same mental bearer that is both pleasant and unpleasant at once. To be both pleased and displeased by the same aspect of some object, under the same mode of presentation, equally intrinsically, equally seriously, etc., would rebut CONTRARIETY. But no such cases have been presented so far.

Consider the previous case of subjects feeling both positive and negative about smoking. Rather than saying the subject is in one ambivalent-pleasant and unpleasant - mental state directed towards smoking, we might say that the subject is at once in two mental episodes: the subject takes intrinsic pleasure in smoking and takes extrinsic displeasure in doing so (because, for instance, smoking puts his health in danger). Since this is possibly not the very same mental episode that is both pleasant and unpleasant, CONTRARIETY is not rebutted.

Likewise, Larsen and McGraw (2011) present subjects with a bittersweet film so as to assess the mixed emotions it evokes. The stimulus is shown to elicit simultaneous pleasure and unpleasure. But whether, for instance, it is the very same aspect of the film that pleases or displeases the subject (maybe the bitter aspect of such film is distinct from the sweet aspect), or whether only their pleasure or unpleasure is extrinsic, or make-believe, remains un-assessed.

Larsen et al. (2004) investigate the interesting case of "disappointing wins" and "relieving losses" at gambles that, they argue, also elicit mixed emotions. This is very likely to be true, but as they also rightly notice, whether an outcome is counted as pleasant or unpleasant depends on the counterfactual comparisons under which it is considered. A win is pleasant when considered under the "could have lost" mode of presentation, and unpleasant when considered under the "could have won more" mode of presentation. These are clearly two distinct attitudes towards same outcome, and neither is at once pleasant and unpleasant. INDEPENDENCE, again, does not follow.

Possibly the most challenging case of mixed feeling with respect to CONTRA RIETY has been advanced by Greenspan (1980). He cites cases of friendly rivalry, such as feeling both happy and sad at the victory of a friend in a game in which we participated. But even in such difficult cases, different options remain open to the upholder of CONTRARIETY. First, one might take intrinsic pleasure in our friend's victory, but extrinsic unpleasure in the same victory, to the extent that it entails our own defeat. Second, it might be that the same outcome is enjoyed under the "my friend's victory" mode of presentation, and suffered under the "my own defeat" mode of presentation. Yet other options are conceivable (see Kristjansson 2010; Calabi 2011 for further discussions). 
In any event, no clear case in which it is exactly the same fine-grained mental episode which is both pleasant and unpleasant at once has yet been put forward: CONTRARIETY remains a live option. Two worries needs to be dispelled with respect to this "going fine-grained" strategy.

First, a potential issue with the above is whether the fine-grained bearers of pleasantness/unpleasantness, which one needs to consider to secure the contrariety of pleasure and its opposites, are properly mental episodes, rather than aspects or constituents of mental episodes. Those who believe, for instance, that one has only one big mental episode at a time or even in one's whole life, will have to endorse some version of the second option. They will need to replace the above claim that mental episodes are the proper bearers of the property of being pleasant, by the claim that aspects or constituents of mental episodes are the proper bearers of the property of being pleasant. Under this qualification, I shall in what follows assume that the "going fine-grained" strategy is in principle able to counter any objection to the contrariety of pleasures and its opposites stemming from mixed feelings.

A second worry is that by going too fine-grained, one might end up rigidifying the connection between pleasantness (or unpleasantness) and the mental episodes by which it is borne. That is, it would not be possible for a given fine-grained mental episode to be anything but pleasant. If so, it might argued, pleasantness and unpleasantness would not be contraries anymore, for they would accrue to different kinds of bearers. ${ }^{17}$ It would be impossible, for any fine-grained mental episode, not only to be pleasant and unpleasant at once, but also to be pleasant and unpleasant at different times. As an answer, it has to be granted that there is indeed a risk here, but this risk is easily circumscribed. When going fine-grained we should not appeal to the formal objects of pleasure. It is arguably impossible to take pleasure in something without it appearing to us as being good for us in some way (Kenny 1966: 134-5 is the locus classicus for the corresponding claim about emotions). The apparent personal goodness of what we take pleasure in is the formal object of pleasure. When individuating the mental episodes to which pleasantness and unpleasantness accrue, we should therefore not appeal to presentations of values, for once these are held fixed, pleasantness and unpleasantness can no longer alight freely on the mental episodes at stake (e.g. appearance of positive personal value precludes unpleasantness). For the rest, as alluded to above, it is quite possible to enjoy the very same melody during the first hearing, and to enjoy it less during the tenth hearing, intrinsically, without making-believe, under the very same aspect and mode of presentation.

Finally, upholders of INDEPENDENCE are right to complain that asking subjects whether they feel positive or negative about stimulus gives too limited a choice, which prevents the reporting of ambivalent reactions. But the additional option that should be given to subjects is not the possibility of assessing pleasantness and unpleasantness independently. It is, instead, the possibility of assessing the pleasantness/unpleasantness of different aspects or parts of the stimulus, under different modes of presentation of that stimulus, as well as different kinds of pleasantness/unpleasantness.

\footnotetext{
$\overline{{ }^{17} \mathrm{I} \text { am grateful to an anynymous }}$ referee of this journal for having pointed out this issue.
} 


\subsection{The Price of INDEPENDENCE}

If true, the above only shows that INDEPENDENCE is not entailed by the existence of mixed feelings, not that INDEPENDENCE is false. Why then favor CONTRARIETY over INDEPENDENCE? Because INDEPENDENCE has damaging consequences for our natural and scientific understanding of affects.

First, INDEPENDENCE strongly departs from our ordinary thinking about pleasure. Pleasure and unpleasure are antonyms. This antonymy reflects an important conceptual fact: we think of pleasure and unpleasure as contraries. This opposition structures a substantial part of our normal way of thinking and acting. For instance, ceteris paribus, we desire pleasant experiences and are averse to having unpleasant ones. Why would this be so, if pleasure and unpleasure were not opposites? Wouldn't it be, in Findlay's $(1961,177)$ terms "a gross, empirical accident that we uniformly sought the one and avoided the other"? ${ }^{18}$

Besides, if INDEPENDENCE holds, then pleasures and unpleasures are no more of the same kind than are, say, pleasures and beliefs, or unpleasures and suppositions. To say that the same mental episode is both pleasant and unpleasant would be analogous to saying that the same body is both red and heavy. Indeed, the very expressions "valence", "positivity and negativity", and "pleasure and unpleasure" are misleading under INDEPENDENCE for they suggest that positive and negative valences, pleasantness and unpleasantness, are of a same kind, which has to be denied if they are construed as orthogonal dimensions.

How serious is such a departure from ordinary thinking? True, empirical psychology might lead to conceptual revisions. But the revision that INDEPENDENCE calls for is quite radical: we might well lose grip on the concepts of pleasure and unpleasure if we cease to conceive of them as opposites. That is, it is unclear that the scientific concepts of pleasure and unpleasure, as revised by INDEPENDENCE, still have anything to do with our ordinary concepts of the same. The risk, in INDEPENDENCE, is that by advocating a radical revision of the way we conceive of pleasure and unpleasure, it ends up changing the subject.

The second reductio of INDEPENDENCE I want to put forward does not point to its incompatibility with our conceptual scheme, but to a more internal inconsistency. INDEPENDENCE has it that if the same stimuli can elicit both pleasure and unpleasure, we have reason to consider pleasantness and unpleasantness as orthogonal dimensions of experience. Now, if there are mixed feelings of pleasure and unpleasure, there are certainly also mixed feelings of mild and more intense pleasure. Such mixed feelings of pleasures raise an important problem for INDEPENDENCE. By parity of reasoning, the upholder of INDEPENDENCE should say that when the same stimuli elicits both a slight a pleasure (of degree $n$ ), and an more intense pleasure (of degree $n^{+}$ 1), we should consider mildly pleasant and very pleasant as orthogonal, independent dimensions of experience. That is, if the co-occurrence of pleasantness and unpleasantness gives reason to consider them as independent dimensions, then so do the cooccurrence of mild pleasantness and strong pleasantness.

Likewise, there are very probably mixed feelings of pleasure and indolence. The same stimuli might elicit pleasure and hedonic indifference. The same picture might elicit strong

\footnotetext{
${ }^{18}$ Findlay's original objection was targeted at hedonic tones theories of pleasure, but is naturally applicable to INDEPENDENCE.
} 
pleasure with respect to its depictum, but might leave us cold with respect to its composition. Shouldn't the upholders of INDEPENDENCE, then, draw the conclusion that subjects should be asked to assess independently the algedonic positivity, negativity, and neutrality of their experience? Shouldn't these constitute three independent dimensions of experience?

But it does seem absurd to introduce an independent dimension of variation for each degree of pleasantness, including the neutral degree. This strongly suggests that the fact that the same stimuli elicit at once positive and negative affective reactions (or weakly and highly positive reactions) does not entail that positivity and negativity (or low positivity and high positivity) are independent dimensions of variation. Pleasant and unpleasant (polar opposites), mildly pleasant and strongly pleasant (scalar opposites), pleasant and indolent (neutral opposites) can be mixed: they remain contraries.

\section{Conclusion}

I have argued that pleasure has two natural contraries: unpleasure and indolence. Unpleasure is the polar opposite of pleasure; indolence is the neutral opposite of pleasure. This is all compatible with the ubiquity of mixed feelings. Key to my argument has been the close connection between the concepts of polar opposition between pleasure and unpleasure, on the one hand, and of indolence on the other. The connection is as follows. The relation of polar opposition-which relates pleasure to unpleasure - is a sub-species of the relation of contrariety. It relates contrary properties of a same order falling on both sides of a neutral point. It is the existence of such a sui generis pivotal point that structures the pleasure-unpleasure space in a polar way. This is why indolence is crucial to understanding of the opposition between pleasure and unpleasure. To play this structural role, indolences have to be something more that mere mental episodes that are neither pleasures nor unpleasures: they have to constitute a genuine, sui generis, kind of mental episodes.

Acknowledgments I am very grateful to Cain Todd, Otto Bruun, Nicole Osborne, Fabrice Teroni, Anne Meylan, Julien Deonna, Guillaume Fréchette, Wlodek Rabinowicz, Toni Rønnow-Rasmussen, Michael Zimmerman, Kevin Mulligan and to two anonymous referees of this journal for their invaluable comments.

\section{References}

Alston, W. 1967. Pleasure. In The encyclopedia of philosophy, ed. P. Edwards. New York: Macmillan. Aydede, M. 2000. An analysis of Pleasure vis-a-vis pain. Philosophy and Phenomenological Research 61: $537-570$.

Bain, A. 1859. The emotions and the will. London: Joh W. Parker and Son, West Strand.

Bain, A. 1875. The emotions and the will. London: Longman.

Balashov, Y. 1999. Zero-value physical quantities. Synthese 119: 253-286.

Barnes, J. 1969. The law of contradiction. The Philosophical Quarterly 19: 302.

Baumeister, R.F., E. Bratslavsky, C. Finkenauer, and K.D. Vohs. 2001. Bad is stronger than good. Review of General Psychology 5(4): 323-370.

Beebe-Center, J. 1965. The psychology of pleasantness and unpleasantness. New York: Russell \& Russell. Bentham, J. 1996. In An Introduction to the principles of morals and legislation, ed. J. Burns and H. Hart. USA: Oxford University Press. 
Berkeley, G. 1998. Three dialogues between hylas and philonous (Oxford Philosophical Texts). USA: Oxford University Press.

Bouillier, F. 1877. Du Plaisir et de la Douleur. Hachette et cie.

Brentano, F. 1979. Untersuchungen zur Sinnespsychologie. Meiner Verlag.

Brentano, F. 1995. Psychology from an Empirical Standpoint, L. McAlister, ed. London: Routledge, trad. A. C. Rancurello, D. B. Terrell, L. L. McAlister.

Broad, C.D. 1959. Five types of ethical theory. Paterson: Littlefield, Adams.

Burke, E. 1767. A philosophical enquiry into the origin of our ideas of the sublime and beautiful. London: J. Dodsely.

Cacioppo, J.T., and G.G. Berntson. 1994. Relationship between attitudes and evaluative space: A critical review, with emphasis on the separability of positive and negative substrates. Psychological Bulletin 115: 401-423.

Calabi, C. 2011. Emotions et contradictions. In Les Ombres de l’Âme: Penser les émotions négatives, ed. C. Tappolet, F. Teroni, and A. Konzelmann Ziv. Genève: Markus Haller.

Carnap, R. 2002. La Construction Logique du Monde. Paris: Vrin, trad. E. Schwartz, T. Rivain.

Clark, A. 1993. Sensory qualities. USA: Oxford University Press.

Crisp, R. 2006. Reasons and the good. USA: Oxford University Press.

Cruse, D. 1995. Lexical semantics. Cambridge: Cambridge University Press.

Diener, E., and R.A. Emmons. 1984. The independence of positive and negative affect. Journal of Personality and Social Psychology 47: 1105-1117.

Duncker, K. 1941. On pleasure, emotion, and striving. Philosophy and Phenomenological Research 1: 391.

Edwards, R.B. 1975. Do pleasures and pains differ qualitatively? The Journal of Value Inquiry 9: 270-281.

Edwards, R. 1979. Pleasures and pains: A theory of qualitative hedonism. Ithaca: Cornell University Press.

Edwards, J.D., and T.M. Ostrom. 1971. Cognitive structure of neutral attitudes. Journal of Experimental Social Psychology 7(1): 36-47.

Elder, C.L. 1996. Realism and determinable properties. Philosophy and Phenomenological Research 56: 149.

Fales, E. 1990. Causation and universals. London: Routledge.

Feldman, F. 1997. Utilitarianism, hedonism, and desert: Essays in moral philosophy. Cambridge: Cambridge University Press.

Findlay, J. 1961. Values and Intentions. London: Allen \& Unwin.

Fréchette, G. 2013. "Searching for the Self: Early Phenomenological Accounts of Self-Consciousness from Lotze to Scheler". International Journal of Philosophical Studies, to appear.

Geach, P.T. 1969. Contradictories and contraries. Analysis 29: 187.

Goodman, N. 1977. The structure of appearance (reprint of the original 3rd ed. 1977 ed.). Boston: Springer.

Greenspan, P. 1980. Case of mixed feelings: Ambivalence and the logic of emotion. In Explaining emotions, ed. A. Rorty, 223-250. Berkeley: University of California Press.

Hamilton, W. 1882. In Lectures on metaphysics and logic, vol. 1-4, ed. H.L. Mansel and J. Veitch. Edinburgh: William Blackwood and Sons.

Hartmann, N. 1932. Ethics. 3 vols. London: George Allen \& Unwin Ltd. New York: The Macmillan Company, Trad. Stanaton Coit.

Helmholtz, H.V. 1995. In The facts in perception, ed. D. Cahan. Chicago: University of Chicago Press.

Horn, L. 1989. A natural history of negation. Chicago: University of Chicago Press.

Hume, D. 2000. In A treatise of human nature, ed. D. Norton and M. Norton. Oxford: Oxford University Press.

Johansson, I. 2000. Determinables as universals. The Monist 83: 101-121.

Johansson, I. 2001. Species and dimensions of pleasure. Metaphysica 2: 39-71.

Johnson, W. 1964. Logic: Part 1. New York: Dover.

Kant, I. 2006. Anthropology from a pragmatic point of view. Cambridge: Cambridge University Press.

Katz, L. 2006. "Pleasure". plato.stanford.edu.

Kenny, A. 1966. Action, emotion and will. London: Routledge \& Kegan Paul.

Klocksiem, J. 2010. "Pleasure, Desire and Oppositeness" Journal of ethics and social philosophy.

Kristjansson, K. 2010. The trouble with ambivalent emotions. Philosophy 85(4): 485.

Külpe, O. 1895. Outlines of Psychology. Ayer Co Pub.

Larsen, J.T., and A.P. McGraw. 2011. Further evidence for mixed emotions. Journal of Personality and Social Psychology 100: 1095.

Larsen, J., A. McGraw, B. Mellers, and J. Cacioppo. 2004. The agony of victory and thrill of defeat: Mixed emotional reactions to disappointing wins and relieving llosses. Psychol Sci 15: 325-330.

Larsen, J.T., C.J. Norris, A.P. McGraw, L.C. Hawkley, and J.T. Cacioppo. 2009. The evaluative space grid: a single-item measure of positivity and negativity. Cognition and Emotion 23: 453-480. 
Lehrer, A., and K. Lehrer. 1982. Antonymy. Linguistics and Philosophy 5: 483-501.

Lipps, T. 1903. Leitfaden der Psychologie, 1st ed. Leipzig: Verlag von Wilhelm Engelmann.

Locke, J. 2008. An Essay concerning Human Understanding (Oxford World's Classics). OUP Oxford.

Long, A., and D. Sedley. 1987. The hellenistic philosophers: Translations of the principal sources, with philosophical commentary. Cambridge: Cambridge University Press.

Lotze, H. 1888. Microcosmus: An essay concerning man and his relation to the world. New York: Scribner \& Welford.

Marshall, H.R. 1889. III: The classification of pleasure and pain. Mind XIV: 511-536.

Marshall, H. 1894. Pain, pleasure and aesthetics. London: Macmillan.

Massin, O. 2011. Joies amères et douces peines. In Les ombres de l'âme, penser les émotions négatives, ed. C. Tappolet, A.F. Teroni, and A. Konzelmann Ziv, 55-70. Genève: Markus Haller.

Massin, O. 2013a. The intentionality of pleasures and others feelings, a brentanian approach. In Themes from Brentano, ed. D. Fisette and G. Fréchette, 307-337. Amsterdam: Rodopi.

Massin, O. 2013b. Determinables and brute similarities. In Johanssonian investigations essays in honour of Ingvar Johansson on his seventieth birthday, ed. C. Svennerlind, J. Almäng, and R. Ingthorsson, 388420. Heusenstamm: Ontos Verlag.

Massin, O., and M. Hämmerli. 2014. Mélanges Chromatiques: la théorie brentanienne des couleurs multiples à la loupe. In Vers une philosophie scientifique. Le programme de Brentano, ed. C.-E. Niveleau. Paris: Demopolis.

Mezes, S.E. 1895. Pleasure and pain defined. The Philosophical Review 4: 22.

Mill, J. 1869. In Analysis of the phenomena of the human mind, ed. A. Findlater, A. Bain, G. Grote, and J.S. Mill. London: Longmans, Green, Reader and Dyer.

Mill, J.S. 2002. "Utilitarianism" and "On Liberty": Including "Essay on Bentham" and Selections from the Writings of Jeremy Bentham and John Austin. Wiley-Blackwell.

Mulligan, K. 1991. Colours, corners and complexity: Meinong and wittgenstein on some internal relations. In Existence and explanation: Essays in honor of Karel Lambert, ed. B.C. van Fraassen, B. Skyrms, and W. Spohn, 77-101. Dordrecht: Kluwer.

Mulligan, K. 2009. "Emotion and Value". Oxford University Press.

Plato. 1993. Philebus. Hackett Publishing Co, Inc.

Plochmann, G.K. 1950. Some neglected considerations on pleasure and pain. Ethics 61(1): 51-55.

Rachels, S. 2004. Six theses about pleasure. Philosophical Perspectives 18: 247-267.

Russell, B. 1958. What is mind? The Journal of Philosophy 55: 5.

Russell, J.A. 1979. Affective space is bipolar. Journal of Personality and Social Psychology 37(3): 345-356.

Russell, B. 1995. The analysis of mind. London: Routledge.

Russell, J.A., and J.M. Carroll. 1999. On the bipolarity of positive and negative affect. Psychological Bulletin 125(1): 3-30.

Ryle, G. 1954. Pleasure. Proceedings of the Aristotelian Society 28: 135-146.

Schimmack, U. 2001. Pleasure, displeasure, and mixed feelings: are semantic opposites mutually exclusive? Cognition \& Emotion 15(1): 81-97.

Schlick, M. 1962. Problems of ethics. New York: Dover Publications.

Sidgwick, H. 1981. Methods of ethics. Indianapolis: Hacket Publishing Company.

Sprigge, T. 1988. The rational foundations of ethics. London: Routledge \& Kegan Paul.

Stout, G.F. 1902. Analytic psychology. London New York: Sonnenschein Macmillan.

Stumpf, C. 1928. Gefühl und Gefühlsempfindung. Leipzig: Verlag von Johann Ambrosis Barth.

Tappolet, C. 2005. Ambivalent emotions and the perceptual account of emotions. Analysis 65(3): $229-233$.

Titchener, E. 1908. Lectures on the elementary psychology of feeling and attention. New York: The Macmillan Company.

Trigg, R. 1970. Pain and emotion. Oxford: Clarendon Press.

Verri, P. 1781. Discorsi Sull'indole del Piacere e del Dolore, Sulla Felicitae sulla Economia Politic. Milan: Giuseppe Marelli.

Von Wright, G. 1963. The varieties of goodness. London: Routledge \& Kegan Paul.

Watson, D. 2000. Mood and temperament. New York: The Guilford Press.

Watson, D., and A. Tellegen. 1985. Toward a consensual structure of mood. Psychological Bulletin 98: 219-235.

Wohlgemuth, A. 1917. On the feelings and their neural correlates, with an examination of the nature of pain. British Journal of Psychology 8: 423-476.

Woods, J. 1969. Predicate ranges. Philosophy and Phenomenological Research 30: 259.

Young, P.T. 1918. An experimental study of mixed feelings. The American Journal of Psychology 29: 237. 